\title{
COMPOSICIÓN QUÍMICA DEL ACEITE ESENCIAL DE Caesalpinia spinosa "TARA", EVALUACIÓN ANTIOXIDANTE Y EFECTO ANTIBACTERIANO FRENTE A Streptococcus mutans
}

\section{Chemical compositium of essential oil from Caesalpinia spinosa "tara", antioxidant evaluation and antibacterial effect against Streptococcus mutans}

Américo J. Castro ${ }^{1}$, Norma J. Ramos ${ }^{1}$, José R. Juárez, Julio R. Ruíz ${ }^{1}$, Fritz F. Choquesillo ${ }^{1}$, Juan J. Ponce ${ }^{1}$, Omar H. Santa María ${ }^{1}$, Alfredo A. Castillo ${ }^{1}$, Denis A. García ${ }^{1}$, Jackeline Escudero ${ }^{1}$, Arnaldo J. Navarro ${ }^{1}$, Susan A. Huamán ${ }^{1}$, Merritt B. Machaca ${ }^{1}$, Paúl I. Gutiérrez ${ }^{1}$, Emilio G. Ramirez ${ }^{2}$, Sixto Gonzales ${ }^{3}$

${ }^{1}$ Instituto de Investigación en Ciencias Farmacéuticas y Recursos Naturales "Juan de Dios Guevara”, Facultad de Farmacia y Bioquímica, Universidad Nacional Mayor de San Marcos. ${ }^{2}$ Escuela de Formación Profesional de Farmaciay Bioquímica, Universidad Nacional de San Cristóbal de Huamanga. ${ }^{3}$ Laboratorio de Toxicología del Instituto de Medicina Legal del Ministerio Público

\section{RESUMEN}

Se determinó la composición química del aceite esencial de Caesalpinia spinosa, obtenido por el método de destilación por arrastre con vapor de agua con un rendimiento de $0,125 \% \mathrm{v} / \mathrm{p}$, así como su capacidad antioxidante y actividad antibacteriana frente a Streptococcus mutans ATCC 35668. Para la identificación de los constituyentes químicos se emplearon Cromatografía de Gas y Espectrometría de Masas (CG/EM), encontrándose 23 compuestos, de los cuales destacan en mayor porcentaje: pelargonaldehído $(11,21 \%)$; dihydro-neoclovene-(i) (5,51\%); naphthalene,1,2,3,5,6,8a-hexahydro-4,7-dimethyl-1-(1-methylethyl)-,(15-CIS)- (4,87\%) y dihydro-cis-alfa-copaene-8-ol (4,13\%). La evaluación de la actividad antioxidante se realizó aplicando los métodos de 2,2-difenil-1picrilhidracilo (DPPH) y del radical ácido 2,2'-azino-bis-(3-etilbenzotiazolin-6-sulfónico) (ABTS ${ }^{\bullet+}$ ), determinándose que el IC 50 para los dos métodos fue $>200 \mu \mathrm{L} / \mathrm{mL}$, utilizando como referente de captación para ambos trolox ${ }^{\circledR}$, que presentó IC50 3,8 $\mu \mathrm{g} / \mathrm{mL}$ ). La determinación de la actividad antibacteriana se efectuó por el método de difusión en agar, donde el aceite de tara en concentraciones de 100,50 y $25 \%$, formó halos de inhibición de 21, 18 y $16 \mathrm{~mm}$, respectivamente, frente a Streptococcus mutans, siendo el control negativo etanol $96^{\circ}$ y el control positivo ciprofloxacino, que presentó un halo de $25 \mathrm{~mm}$. Se concluyó que la composición química del aceite esencial obtenido de Caesalpinia spinosa presenta actividad antioxidante, aunque no es significativa en comparación con el compuesto de referencia trolox ${ }^{\circledR}$, mientras que su actividad antibacteriana en las concentraciones utilizadas tuvo resultados significativos.

Palabras clave: Aceite esencial, antioxidante, antibacteriano, Caesalpinia spinosa, Streptococcus mutans ATCC 35668.

\section{SUMMARY}

Was determinated chemical composition of essential oil from Caesalpinia spinosa, obtained by stripping with steam method, with a yield of $0,125 \% \mathrm{v} / \mathrm{w}$, as well as its antioxidant capacity and antibacterial effect against Streptococcus mutans ATCC 35668 . To identify chemical constituents_were_employed Gas Chromatography and Mass Spectrometry (GC/MS), finding 23 compounds, being in greater quantity: pelargonaldehído (11,21\%); dihydro-neoclovene-(i) (5,51\%); naphthalene,1,2,3,5,6,8a-hexahydro-4,7-dimethyl1-(1-methylethyl)-,(15-CIS)- $(4,87 \%)$ y dihydro-cis-alfa-copaene-8-ol $(4,13 \%)$. Evaluation of antioxidant activity was performed using the methods of 2,2-diphenyl-1-picrylhydrazyl (DPPH) and acid radical 2,2'-azino-bis- (3-etilbenzotiazolin-6-sulfonic acid) (ABTS ${ }^{\bullet+}$ ), determining that IC 50 to both methods was $>200 \mu \mathrm{L} / \mathrm{mL}$, using as captation reference trolox ${ }^{\circledR}$, which had IC 50 3,8 $\mu \mathrm{g} / \mathrm{mL}$. The determination of antibacterial effect was made by agar diffusion method, where 100, 50 and $25 \%$ tara oil concentrations, produced inhibition halos of 21, 18 and $16 \mathrm{~mm}$, respectively, against Streptococcus mutans, being negative control ethanol 96o and positive control ciprofloxacin, which presented a halo of $25 \mathrm{~mm}$. Were concluded that the chemical composition of the essential oil obtained from Caesalpinia spinosa has antioxidant activity, although is not significant compared to the reference compound Trolox ${ }^{\circledast}$, while its antibacterial activity at used concentrations had significant results.

Keywords: Antioxidant essential oil, antibacterial, Caesalpinia spinosa, Streptococcus mutans.

\section{INTRODUCCIÓN}

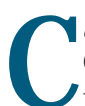
aesalpinia spinosa “tara”, es un árbol de la familia Caesalpiniaceae, nativo del Perú, utilizado en la medicina tradicional como fuente sostenible de taninos, los cuales se concentran principalmente en sus frutos, que son vainas aplanadas y encorvadas de color naranja con cuatro a siete semillas ovoides ligeramente aplanadas. Las vainas también son muy utilizadas en el curtido de cueros, con un uso tan intensivo que coloca al Perú como el mayor productor de tara a nivel mundial.

Sus aceites esenciales, localizados en flores, hojas y frutos, son una mezcla de terpenos, serquiterpenos y sustancias aromáticas, por lo que presenta actividad antioxidante al igual que los aceites de otras especies, como Origanum vulgare (orégano), Rosmarinus officinalis L. (romero), Minthostachys mollis (muña), Erythroxylum novogranatense (coca) y Schinus molle L. (molle) ${ }^{1-3}$. Diferentes estudios han demostrado que los aceites esenciales también tienen actividad antimicrobiana, conociéndose en particular que los de Erythroxylum novogranatense y Minthostachys mollis inhiben el crecimiento y la adhesión de bacterias a la placa dental ${ }^{4-5}$.

Streptococcus mutans es una bacteria Gram positiva, anaeróbica facultativa, que se encuentra normalmente dentro del complejo, y no completamente investigado, 
Tabla 1. Preparación de las muestras para la determinación de la actividad antibacteriana.

\begin{tabular}{lccc}
\hline \multicolumn{1}{c}{ Muestras } & $\mathbf{1 0 0 \%}(\boldsymbol{\mu l})$ & $\mathbf{5 0 \%}(\boldsymbol{\mu l})$ & $\mathbf{2 5 \%}(\boldsymbol{\mu l})$ \\
\hline Aceite esencial & 100 & 50 & 25 \\
Etanol $96^{\circ}(\mathrm{mL})$ & - & 50 & 75 \\
Total $(\mathrm{mL})$ & 100 & 100 & 100 \\
\hline
\end{tabular}

ecosistema bucal humano. Cuando la placa dental se forma, este microorganismo tiende a adherirse en ella contribuyendo a la patología bucal.

No existiendo estudios sobre el aceite esencial de las vainas de Caesalpinia spinosa "tara", se propuso como objetivo elucidar su composición química, determinar su capacidad antioxidante y evaluar su acción antibacteriana frente a Streptococcus mutans ATCC 35668.

\section{MATERIAL Y MÉTODOS}

La investigación es de tipo experimental, de diseño transversal, analítico, prospectivo y longitudinal.

\section{Colecta del material biológico}

Las vainas de Caesalpinia spinosa "tara", fueron colectadas en la provincia de Huanta, región Ayacucho y la clasificación taxonómica se realizó en el Museo de Historia Nacional de la Universidad Nacional Mayor de San Marcos.

\section{Obtención del aceite esencial}

Se seleccionaron $16 \mathrm{~kg}$ de vainas de tara, se retiraron las semillas y se las trató en un sistema de destilación por arrastre con vapor de agua obteniéndose un rendimiento de $0,125 \% \mathrm{v} / \mathrm{p}$.

\section{Determinación de los compuestos químicos}

Se realizó en un Cromatógrafo de Gases modelo Clarus 6oot acoplado a un Espectrómetro de Masas (CG/EM) Perkin Elmer Turbo MASS, en las siguientes condiciones: columna capilar de silica gel fundida de $30 \mathrm{~m}$ de largo, diámetro o,25 $\mu$, temperatura inicial $60^{\circ} \mathrm{C}$, tiempo de espera de 60 minutos para llegar a temperatura final de $230^{\circ} \mathrm{C}$, temperatura de inyección: $250^{\circ} \mathrm{C}$, volumen de inyección: 1 $\mu \mathrm{L}$. La detección y elucidación de los componentes químicos fue por comparación con los estándares de espectros de masas de las respectivas bibliotecas.

\section{Determinación de la actividad antioxidante \\ Método 2,2-difenil-1-picrilhidracilo (DPPH)}

Se prepararon diluciones del aceite esencial en concentraciones de 200, 150, 100 y $50 \mu \mathrm{L} / \mathrm{mL}$ en etanol absoluto. $20 \mathrm{mg}$ de DPPH se trataron con $50 \mathrm{~mL}$ de metanol obteniéndose una solución stock de $40 \mathrm{mg} / 100 \mathrm{~mL}$, la que se conservó en frasco de vidrio de color ámbar y en refrigeración. Asimismo, se preparó una solución de trabajo de DDPH, con 1,7 mL de solución stock que se llevaron a volumen final de $20 \mathrm{~mL}$ con metanol, obteniéndose a $517 \mathrm{jm}$ una absorbancia entre o,600 - 0,7000. En el procedimiento se calibró el espectrofotómetro con un blanco de $400 \mu \mathrm{L}$ de etanol absoluto y $800 \mu \mathrm{L}$ de metanol. Se colocaron en tubo de ensayo $400 \mu \mathrm{L}$ del aceite esencial (concentraciones de 50, 100, 150 y $200 \mu \mathrm{L} / \mathrm{mL}$ ) y $800 \mu \mathrm{L}$ de la solución de trabajo de DPPH, dejando reposar durante 30 minutos protegido de la luz, para luego realizar las lecturas en espectrofotómetro de luz UV-Visible a $517 \mathrm{jm}$. Se utilizó un control de DPPH en donde se reemplazó el aceite esencial por etanol absoluto. Cada ensayo se realizó por triplicado. También se preparó un blanco de muestra (un tubo para cada concentración) que contenía $400 \mu \mathrm{L}$ del aceite esencial de tara y $800 \mu \mathrm{L}$ de metanol.

Método de captación del radical ácido 2,2'-azinobis-(3-etilbenzotiazotiazolin-6-sulfónico $\left(A B T S^{\bullet+}\right)$ A partir del aceite esencial se prepararon diluciones de 150, 100 y $50 \mu \mathrm{L} / \mathrm{mL}$, utilizando etanol absoluto como

Tabla 2. Composición química del aceite esencial de Caesalpinia spinosa "tara".

\begin{tabular}{|c|c|c|}
\hline Componentes químicos & $\begin{array}{l}\text { Tiempo de } \\
\text { retencion (TR) }\end{array}$ & $\%$ \\
\hline Pelargonaldehido & 17,28 & 11,21 \\
\hline Dihydro-neoclovene-(i) & 36,94 & 5,51 \\
\hline Naphthalene,1,2,3,5,6,8a-hexahydro-4,7-dimethyl-1-(1-methylethyl)-, (1S-CIS)- & 35,72 & 4,87 \\
\hline Dihydro-cis-.alpha.-copaene-8-ol & 38,95 & 4,13 \\
\hline 1H-cycloprop [E]azulene, decahydro-1, 1,7-trimethyl-4-methylene-, [1AR-(1a.alpha., 4 a.alpha., 7. & 35,43 & 4,07 \\
\hline Naphthalene,1,2,4a,5,6,8a-hexahydro-4,7-dimethyl-1-(1-methylethyl)-,[1S-(1.alpha.,4a.alpha.,8A & 34,81 & 3,09 \\
\hline 2-pentadecanone, 6,10,14-trimethyl & 47,07 & 2,93 \\
\hline Naphthalene,1,2,3,4,4a,5,6,8A-octahydro-7-methyl-4-methylene-1-(1-methylethyl)-, (1.alpha.,4A.alph & 33,85 & 2,87 \\
\hline N-hexadecanoic acid & 50,87 & 2,63 \\
\hline Cyclohexane,1,2-dimethyl-3,5-bis(1-methylethenyl)- & 37,14 & 2,62 \\
\hline Tricyclo[4.4.0.0(2,7)]dec-3-ene,1,3-dimethyl-8-(1-methylethyl)-, & 29,68 & 2,47 \\
\hline Decanal; 1-decanal & 21,97 & 2,23 \\
\hline 2,4-nonadienal & 12,18 & 2,20 \\
\hline 2-propen-1-ol, 3-phenyl-, acetate & 32,45 & 1,63 \\
\hline Caryophyllene & 31,57 & 1,58 \\
\hline 1-hexanal & 5,48 & 1,38 \\
\hline 2-nonenal & 19,86 & 1,34 \\
\hline 2-undecenal & 28,98 & 1,28 \\
\hline Cyclohexanone,5-methyl-2-(1-methylethylidene)-, (r)-1-caprialdehido & 23,66 & 1,21 \\
\hline 1-caprialdehido & 12,67 & 0,98 \\
\hline Thymol & 25,89 & 0,95 \\
\hline Ácido octanoico & 20,36 & 0,89 \\
\hline 2,4-nonadienal & 12,18 & 0,08 \\
\hline
\end{tabular}




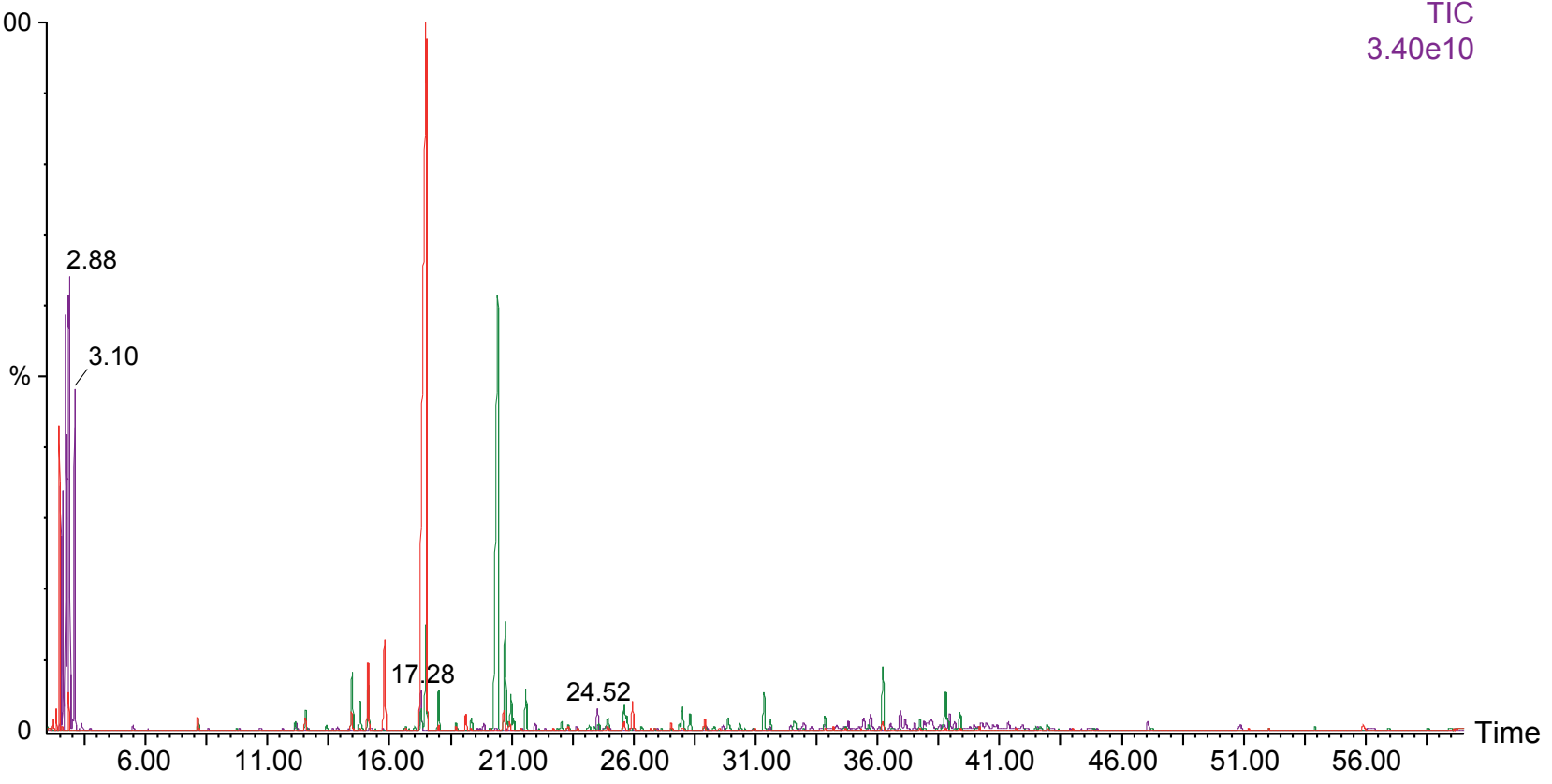

Figura 1. Cromatograma de Gas del aceite esencial de Caesalpinia spinosa "tara".

solvente. Se preparó una solución acuosa stock de $\mathrm{ABTS}^{\bullet+}$ $7 \mathrm{mM}$ y se le añadió persulfato de potasio $2,45 \mathrm{mM}$ para activar la solución; se dejó reaccionar por 16 horas al medio ambiente y en oscuridad. En el procedimiento se diluyó la solución stock de $\mathrm{ABTS}^{\bullet+}$ en etanol absoluto hasta obtener una absorbancia entre $0,700 \pm 0,02$ a 734 Đm, obteniéndose así la solución de trabajo de $\mathrm{ABTS}^{*+}$. Se calibró el espectrofotómetro con un blanco que contenía $20 \mu \mathrm{L}$ de etanol absoluto y $980 \mu \mathrm{L}$ de agua destilada. Se colocaron $20 \mu \mathrm{L}$ de aceite esencial en tubos de ensayo (concentraciones de 150 , 100 y $50 \mu \mathrm{L} / \mathrm{mL}$ ) y 980 $\mu \mathrm{L}$ de la solución de trabajo, dejándose en reposo por 7 minutos y leyéndose la absorbancia a $734 \mathrm{\eta m}$. El mismo procedimiento se realizó para el control $\mathrm{ABTS}^{\bullet+}$, pero reemplazando la muestra por solvente. Cada ensayo se hizo por triplicado.

\section{Determinación de la actividad antibacteriana}

El método consistió en enfrentar muestras del aceite esencial de tara, diluidas con etanol de $96^{\circ}$ para lograr concentraciones de 100, 50 y $25 \%$ (tabla 1), contra la cepa de estudio, Streptococcus mutans ATCC 35668, en agar solido Mueller Hinton con el objeto de evidenciar la formación de halos de inhibición de crecimiento bacteriano.

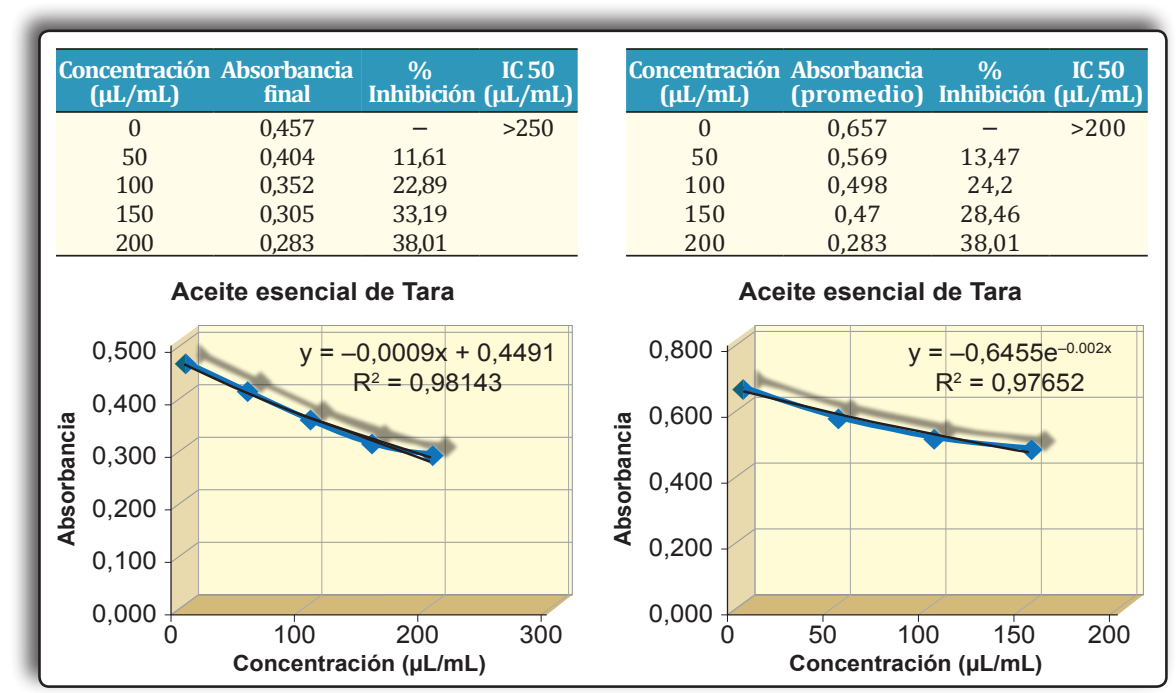

Figura 2. Curva de captación de DPPH y $\mathrm{ABTS}^{++}$del aceite esencial de tara.



Figura 3.Curva decaptación deDPPH delTrolox®. 
Tabla 3. Formación de halos de inhibición de Streptococcus mutans en agar Mueller Hinton, empleando el método de difusión en agar.

\begin{tabular}{ccc}
\hline Muestras & Concentración (\%) $\begin{array}{c}\text { Streptococcus mutans } \\
\text { (Halos de inhibición } \\
\text { en mm) }\end{array}$ \\
\hline Aceite esencial de & 100 & 21 \\
"tara" & 50 & 18 \\
\multirow{2}{*}{ Control negativo } & 25 & 16 \\
& Etanol 96 & - \\
& Ciprofloxacino & 25 \\
\hline
\end{tabular}

Para la preparación de la suspensión del inóculo, el cultivo de la bacteria fue reactivado en solución salina al o,9\%. Para la preparación de las placas, el agar Müeller Hinton se reconstituyó en agua destilada y se dejó en medio ambiente hasta alcanzar $45^{\circ} \mathrm{C}$. Se trataron $100 \mu \mathrm{L}$ de suspensión del inóculo por cada $200 \mathrm{~mL}$ del medio de cultivo, se homogeneizó y se repartió en placas Petri dejando en reposo hasta la solidificación. Se hicieron pozos con un sacabocado de $10 \mathrm{~mm}$ de diámetro en las placas. Para la inoculación e incubación de las muestra, se colocaron $100 \mu \mathrm{L}$ del aceite esencial -en la concentración correspondiente- en los respectivos pozos y se dejó en reposo a temperatura ambiental por una hora para lograr mayor difusión. Luego se llevaron las placas a $37^{\circ} \mathrm{C}$ por 24 horas en condiciones anaerobias. Las pruebas se realizaron por triplicado. Para los controles se utilizó etanol de $96^{\circ}$ y discos de ciprofloxacino $5 \mu \mathrm{g}$. Después de la incubación se observó la presencia de halos de inhibición y se realizó la medida del diámetro.

\section{RESULTADOS}

Se obtuvo un rendimiento de $0,125 \% \mathrm{v} / \mathrm{p}$ de aceite esencial de las vainas de Caesalpinia spinosa "tara", por el método de destilación por arrastre de vapor de agua.

En el aceite esencial se elucidaron las estructuras de 23 componentes químicos con la aplicación del método de Cromatografía de Gases / Espectrometría de Masas (CG/ EM), los cuales se muestran en las figura 1 y en la tabla 2.

Los resultados obtenidos en la determinación de la actividad antioxidante del aceite esencial por los métodos de DPPH y $\mathrm{ABTS}^{\bullet+}$ se presentan en las figuras 2 y 3.

Los resultados en la evaluación de la actividad antibacteriana del aceite esencial de Caesalpinia spinosa
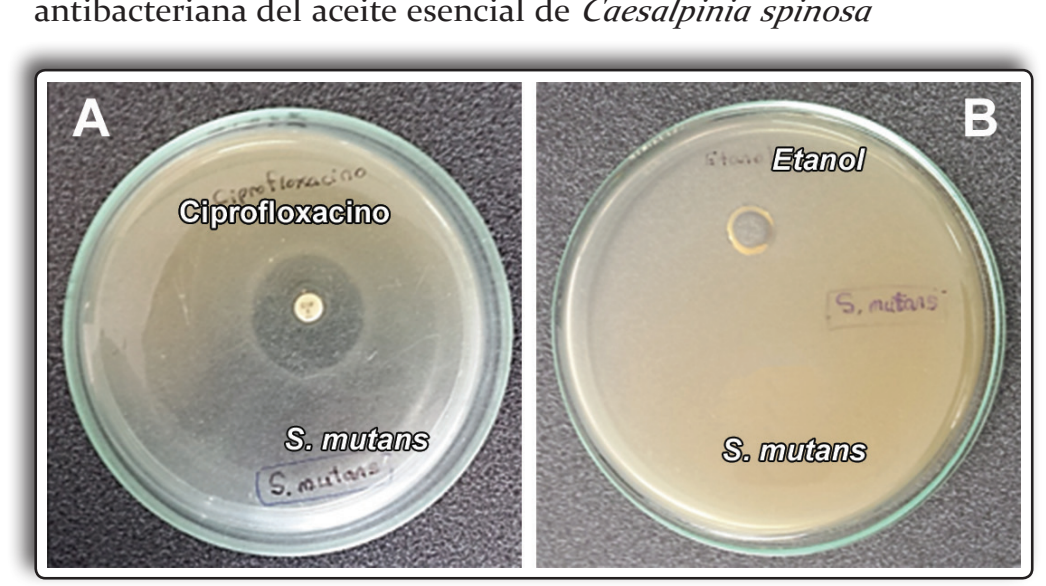

Figura 4. Ciprofloxacino (A) y etanol (B) contra Streptococcus mutans. "tara" frente a Streptococcus mutans, se clasificaron de acuerdo a las concentraciones utilizadas del aceite esencial y se presentan en las figuras 4, 5 y tabla 3.

El porcentaje de inhibición para ambos métodos se calculó de acuerdo a la siguiente expresión:

$$
\% \text { Inhibición }=\frac{\left(\mathrm{Abs}_{\mathrm{ABTS} \bullet+}-\mathrm{Abs}_{\text {muestra }}\right)}{\mathrm{Abs}_{\mathrm{ABTS} \bullet+}} \times 100
$$

\section{DISCUSIÓN}

La composición química de los aceites esenciales no siempre es la misma para cualquier especie vegetal; depende de factores intrínsecos como la zona geográfica, forma de cultivo y medio ambiente. Asimismo, el tipo de extracción también influye en su composición y rendimiento. Los aceites esenciales presentes en especies vegetales suelen ser volátiles, aromáticos, inmiscibles con el agua y de baja densidad. Se les atribuye propiedades: antibacteriana, antioxidante, antifúngica, antiinflamatoria, antiviral, cicatrizantey anti Helicobacter pylori, entre otras ${ }^{6,7}$.

Acerca de Caesalpinia spinosa "tara”, se han realizado investigaciones diversas sobre la aplicación de los extractos acuosos, hidroalcohólico y alcohólico, que reportaron interesantes resultados, como los efectos cicatrizante de su tintura hidroalcohólica, atribuido a su contenido de saponinas, flavonoides y taninos ${ }^{8}$; antibacteriano, del extracto etanólico al 5, 10, 20 y 30\% sobre Streptococcus mutans ${ }^{9}$; y antiinflamatorio, del extracto vehiculizado en pasta dental, en el tratamiento de gingivitis marginal crónica ${ }^{10}$.

En la composición química del aceite esencial, se identificaron 23 componentes, destacando en mayor porcentaje cuantitativo: pelargonaldehído (11,21\%); dihidro-neocloven-(i) $\quad(5,51 \%)$; naftalen,1,2,3,5,6,8ahexahydro-4,7-dimetil-1-(1-metiletil)-,(1S-CIS)$(4,87 \%)$ y dihidro-cis-alfa-copaen-8-ol (4,13\%). En esta composición es notable la presencia de componentes de hidrocarburos saturados, insaturados, ácidos y derivados de ácidos que suelen ser de baja bioactividad frente a metabolitos secundarios que presentan grupos fenólicos,

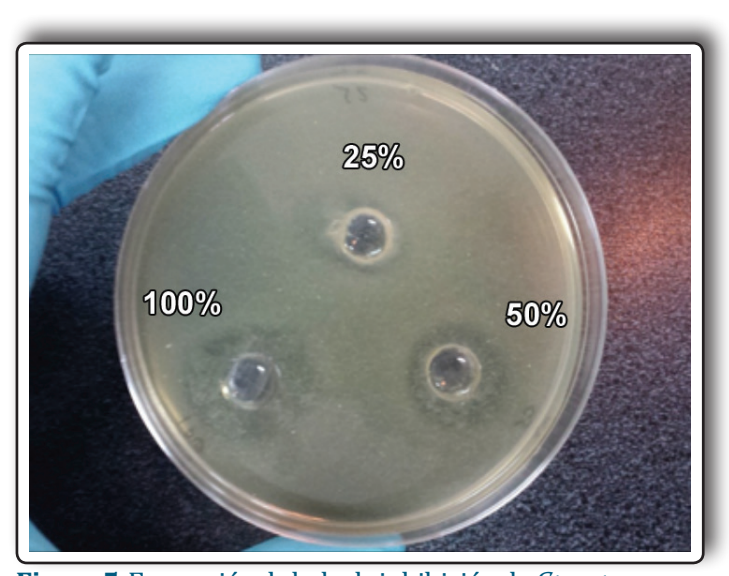

Figura 5. Formación de halo de inhibición de Streptococcus mutans en concentraciones de 100, 50 y $25 \%$. 
alcohólicos y cetónicos, a los cuales se les atribuye acción bactericida y bacterioestática ${ }^{11-12}$.

En cuanto a la patología bucal, se sabe que algunas bacterias tienen la capacidad de adherirse a tejidos blandos, como es el caso de Streptococcus salivarius, mientras que otras, como Streptococcus mutans y Streptococcus sanguinis, se adhieren al esmalte dental ${ }^{14}$, lo que genera múltiples problemas como inflamaciones, infecciones, retracción de las encías, etc., siendo el más resaltante la caries dental, en donde el agente etiológico microbiano más común es Streptococcus mutans ${ }^{15,16}$.

Aunque la actividad antioxidante de los aceites esenciales será variable cuando sea ensayada en diversos sistemas, se sabe que es producto de la presencia compuestos fenólicos, aunque está reportado que no son los únicos que la generan, sino también los terpenos y terpenoides ${ }^{20}$.

Se ha señalado que el aceite esencial de Erythroxylum coca Lam. "coca Huánuco", posee fitocompuestos como $\beta$-pineno, $\beta$-mirceno, nerolidol, fitol, nanocosano y ácido metil ester $7,10,13$ hexadecatrienoico, que participarían en los sistemas redox biológicos con capacidad antioxidante ${ }^{19}$; mientras que otro estudio atribuye al aceite obtenido de las hojas de esta misma especie, en su variedad (Morris) Hieron, var. Truxillense (Rugby) Plowman "coca", actividad antioxidante y antibacteriana frente a Streptococcus mutans, debido a los compuestos fenólicos olivetol y salicilato de metilo que contiene ${ }^{20}$.

Respecto a la actividad antibacteriana, se sabe que también están involucradas, entre otras, las estructuras fenólicas contenidas en los aceites.

Para Streptococcus mutans, la literatura señala que es susceptible a determinados aceites esenciales, entre ellos, el obtenido de Erythroxylum novogranatense "coca Huánuco", con una Concentración Mínima Inhibitoria (CMI) de o,625 $\mu \mathrm{L} / \mathrm{mL}$ para la cepa ATCC $3566813^{19}$; mientras que el extracto alcohólico de las hojas de la misma planta, en su variedad (Morris) Hieron, var. Truxillense (Rugby) Plowman "coca", tiene efecto antibacteriano a las concentraciones de 250 , 500,1000 y $1500 \mu \mathrm{g} / \mu \mathrm{L}^{21}$. Otro estudio, orientado al aceite esencial Lippia sidoides, encontró, entre otros componentes, timol $(56,7 \%)$ y carvacrol $(16,7 \%)$ y demostró efecto antibacteriano frente a Streptococcus mutans y Candida albicans, resaltando la gran potencialidad de esta planta contra patógenos orales ${ }^{22}$.

\section{CONCLUSIÓN}

La composición química del aceite esencial de Caesalpinia spinosa "tara" no mostró efecto significativo de actividad antioxidante con los métodos utilizados de DPPH y ABTS $^{\circ+}$; asimismo, presentó actividad antibacteriana significativa frente a Streptococcus mutans ATCC 35668.

\section{REFERENCIAS BIBLIOGRÁFICAS}

1. Saccheti G, et al. Comparative evaluation of 11 essentials oils of different origins as functional antioxidants, antiradical, and antimicrobial in food. Food Chemistry. 2005; 91(4): 621-32.
2. Tomaino A, et al. Influence of heating on antioxidant activity and the chemical composition of some spice essential oils. Food Chemistry. 2005; 89: 549-54.

3. Takarada K, Kimizuka R, Takahashi N, Honma K, Okuda $\mathrm{K}$, Kato T. A comparison of the antibacterial efficacies of essential oils against oral pathogens. Oral Microbiol Immunol. 2004; 19(1): 61-4.

4. Li SC. Propiedades inhibitorias en el crecimiento de hongos oportunistas in vitro de Erythroxylum coca y Erythroxylum novogranatense Var. Truxillense (mate de coca). [Tesis para optar al Título Profesional de Químico Farmacéutico]. Universidad Nacional Mayor de San Marcos. Lima, 1994.

5. Díaz LK. Determinación de la actividad antibacteriana in vitro de Minthostachys mollis Griseb (muña) frente a bacterias orales de importancia estomatológica. [Tesis para optar al título profesional de Cirujano Dentista]. Facultad de Odontología, Universidad Nacional Mayor de San Marcos. Lima, 2005.

6. Bandoni A. Los recursos vegetales aromáticos en Latinoamérica, su aprovechamiento Industrial para la producción de aromas y sabores. Buenos Aires: Edit. UNLP-CYTED; 2000.

7. Lahlou M. Methods to study the phytochemistry and bioactivity of essential oils. Phytother Res. 2004; 18: 435-48.

8. Escobar BL. Efecto in vitro de diferentes concentraciones de extracto alcohólico de Caesalpinia spinosa (Molina) Kuntze, sobre la viabilidad de Corynebacterium diphtheriae. Rev. Med. Vallejiana. 2008; 5(1): 28-37.

9. Huarino M, Ramos D. Efecto antibacteriano de Caesalpinia spinosa "tara", sobre flora salival mixta. Odontol Sanmarquina. 2012; 15(1): 27-30.

10. Infantes Y. Tratamiento de la gingivitis Marginal Crónica con pasta dental de Caesalpinia spinosa "tara" en niños de 8 a 10 años. [Tesis para obtener el Título Profesional de Cirujano Dentista]. Universidad San Martin de Porres. Lima, 2004.

11. Bruneton J. Farmacognosia. Fitoquímica. Plantas medicinales. $2^{\mathrm{da}}$ ed. Zaragoza: Acribia; 2001.

12. Kuklinski C. Farmacognosia. Estudio de las drogas y sustancias medicamentosas de origen natural. Barcelona: Omega; 2003.

13. Castro A. y col. Composición química del aceite esencial de las hojas de Erythroxylum coca Lam. Var. "coca Huánuco", actividad antioxidante y antibacteriana in vitro, frente a Streptococcus mutans y diseño de una formulación farmacéutica. Proyecto Multidisciplinario del Vicerrectorado de Investigación. Lima: Universidad Nacional Mayor de San Marcos; 2012.

14. Ross, W, Holbrook PW. Microbiología bucal y clínica. México DF: Editorial Científica PLM, S.A. C.V; 1985.

15. Moromi NH, Martínez CE, Ramos PD. Antibacterianos naturales orales: Estudios en la Facultad de Odontología de la Universidad Nacional Mayor de San Marcos. Odontol Sanmarquina. 2009; 12(1): 25-8.

16. Moromi NH, Martínez CE. Efecto del té verde en la formación de la placa bacteriana por Streptococcus mutans. Odontol Sanmarquina. 2006; 9(2): $23-4$.

17. Anchante R. Estudio de la actividad antifúngica del aceite esencial de Origanum vulgare L. [Tesis para optar al 
Título Profesional de Químico Farmacéutico]. Facultad de Farmacia y Bioquímica, Universidad Nacional Mayor de San Marcos. Lima, 1998.

18. Acosta LO. Composición química del aceite esencial de Thymus vulgaris L. "Tomillo" por Cromatografía de Gases-Espectómetro de Masa GC/MS y análisis de su actividad antimicrobiana. [Tesis para optar al Título Profesional del Químico Farmacéutico]. Facultad de Farmacia y Bioquímica, Universidad Nacional Mayor de San Marcos. Lima, 2000.

19. Castro. Composición química del aceite esencial de las hojas de Erythroxylum novogranatense (Morris) "coca", actividad antioxidante y determinación antibacteriana frente a Streptococcus mutans. [Tesis para optar al Grado Académico de Doctor en Farmacia y Bioquímica] Universidad Nacional Mayor de San Marcos. Lima, 2008.

20. Solano OD. Acción antibacteriana del extracto acuoso y metanólico de principios activos totales de Erythroxylum novogranatense (Morris) (Rugby) sobre Streptococcus de la cavidad bucal. [Tesis para optar al Título Profesional del Químico Farmacéutico]. Facultad de Farmacia y
Bioquímica, Universidad Nacional Mayor de San Marcos. Lima, 1996.

21. Borrovic RF. Efecto antibacteriano del extracto alcohólico de la hoja de Erythroxylum novogranatense var. Truxillense (coca) sobre flora mixta salival. [Tesis para optar al título profesional de Cirujano Dentista]. Facultad de Odontología, Universidad Nacional Mayor de San Marcos. Lima, 2006.

22. Botelho MA, et al. Antimicrobial activity essential oil from Lippia sidoides, carvacrol and thymol against oral pathogens. Braz J Med Biol Res. 2007; 40(3): 349-56.

Manuscrito recibido el: 07/07/2016

Aceptado para su publicación el: 19/o9/2016

\section{Correspondencia}

Nombre: Américo J. Castro Luna

Dirección: Jr. Puno 1002 - Lima

e-mail: caslasha3@hotmail.com 